\title{
TEMA 2016: Lupus Eritematoso Sistémico con Anticuer- pos Antinucleares Negativos: Revisión de Tema
}

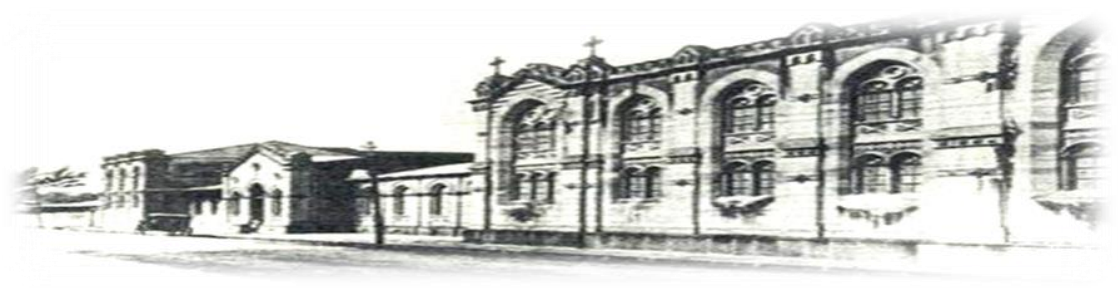

Hospital San Juan de Dios, San José, Costa Rica. Fundado en 1845

Recibido: $\quad$ 03/02/2016

Aceptado: $\quad 15 / 06 / 2016$

\author{
Gustavo Vindas Angulo ${ }^{1}$ \\ Nazaret Salazar Arias ${ }^{2}$ \\ Josué Beita Jiménez $z^{3}$ \\ Michael Valverde Gómez ${ }^{4}$
}

1 Médico Especialista en Medicina Interna. Hospital San Juan de Dios. Académico de la Escuela de Medicina de la Universidad de Costa Rica.

2 Médico General. Universidad de Costa Rica. Correo electrónico: nazaret.sa @ hotmail.com

3 Médico General. Universidad de Costa Rica. Correo electrónico: josuebeita@ hotmail.com

4 Médico General. Universidad de Costa Rica. Correo electrónico: julianjvg@ hotmail.com

\section{RESUMEN}

El Lupus con anticuerpos antinucleares negativos es una entidad clínica poco conocida que forma parte del espectro variable del Lupus eritematoso sistémico, fue descrita inicialmente en 1976 en un 5\% de la población con LES, sin embargo en la actualidad existen dudas respecto a su verdadera incidencia, así como de sus características clínicas, evolución y fisiopatología, a pesar de que se han realizado estudios con la finalidad de esclarecer estas dudas, la información publicada a la actualidad no ha permitido establecer conclusiones en relación a estos puntos.

\section{PALABRAS CLAVE}

Anticuerpos antinucleares. Lupus. ANA negativo. Anticuerpos contra nucleosomas

\section{ABSTRACT}

The ANA-negative lupus is a rare variant of the spectrum of the lupus systemic erythematosus, 
which was first described in 1976with an incidence of $5 \%$ of the SLE population. In nowadays the real incidence is not known. A lot of papers had being done with the purpose to describe the clinical manifestations, the evolution and pathophysiology of this disease, but there are still a lot of doubts that no allowed to make solid conclusion about it.

\section{KEY WORDS}

Antinuclear antibodies. Lupus. ANA negative. Antinucleosome antibodies.

\section{INTRODUCCIÓN}

El Lupus Eritematoso Sistémico (LES) corresponde a una patología ampliamente heterogénea, la cual puede cursar con una gran variedad de manifestaciones clínicas y de laboratorio. Dicha diversidad en las modalidades de presentación, es la que ha llevado a la elaboración de una lista con once criterios diagnósticos, que le permiten al clínico facilitar su reconocimiento. ${ }^{1}$

Dentro de estos criterios se incluye, la presencia de anticuerpos antinucleares (ANA) positivos, en un $95 \%$ de la población diagnosticada con dicha patología. El restante 5\% corresponderían por ende a un segmento poblacional, en quienes no se detecta la presencia de ANA. Estos anticuerpos fueron inicialmente reconocidos por Holborow y colaboradores en 1957, se utilizaron técnicas de inmunofluorescencia, y se describieron inicialmente como anticuerpos capaces de reaccionar contra antígenos ubicados primordialmente en el nucleoplasma. Estudios más recientes, señalan que estos anticuerpos son capaces de reaccionar también contra antígenos ubicados en el citoplasma y membrana celular. A pesar de que son anticuerpos altamente sensibles, su ausencia no constituye un parámetro determinante de la presencia de LES.,3,4

El concepto de Lupus ANA negativo, fue acuñado inicialmente por Koller y colaboradores, en 1976, describieron 5 pacientes, con manifestaciones cutáneas principalmente, dentro de las cuales fue la fotosensibilidad la característica más prevalente. Desde ese momento se han ampliado los estudios en relación a este tema, con la finalidad de determinar la prevalencia exacta de dicha entidad. En estudios posteriores los pacientes con LES ANAs negativos parecen representar menos del $2 \%$ de la población. En relación a este descenso autores describen que deben considerarse los mecanismos de detección, ya que a través del tiempo estos han sido ampliamente variables. ${ }^{5}$

Es por este motivo que consideramos necesaria una revisión que incluya aspectos en la fisiopatología del LES cuando se desarrolla en el contexto de ANAs negativos y bajo qué circunstancias es posible determinar la ausencia de dichos anticuerpos.

\section{DISCUSIÓN}

\section{Mecanismos Inmunológicos en LES}

A la gama de mecanismos inmunológicos que típicamente se relacionan con la etiología del LES, se asocian en su mayoría con factores genéticos y estímulos medioambientales, capaces de generar susceptibilidad para el desarrollo de respuestas inmunológicas anormales. A grandes rasgos, la presencia de antígenos sean exógenos o endógenos, estimulados por factores medioambientales, lleva a la activación de mecanismos de muerte celular y liberación de autoantígenos, que son procesados como péptidos por células presentadoras de antígenos (ACP), dichos péptidos actúan sobre células $\mathrm{T}$ y $\mathrm{B}$, activándolas e induciendo la producción de anticuerpos deletéreos sobre tejidos diana específicos. Dichas vías pueden perpetuarse a través de la liberación de más autoanticuerpos por parte de los tejidos lesionados y con la generación de inmunocomplejos. A esto se suma la alteración en mecanismo genéticos capaces de desarrollar respuestas reguladoras responsables de mediar la tolerancia hacia antígenos propios. ${ }^{1}$

Los principales anticuerpos implicados en el desarrollo del LES son ANAs, estos anticuerpos en su mayoría se desarrollan en respuesta a antígenos nucleares, en especial contra nucleosomas. El nucleosoma se constituye de dímeros de cuatro diferentes histonas (H2A, H2B, H3, H4), las cuales se entrelazan para generar la estructura que da soporte al ADN. Otros antígenos nuclea- 
res responsables del desarrollo de ANAs son el RA33, KU, PCNA, enzimas nucleares y las partículas pequeñas derivadas de ribonucleoproteínas nucleares (snRNP) dentro de las más importantes por sus propiedades antigénicas se encuentra la proteína Smith $(\mathrm{Sm})$, mientras que dentro de las de origen citoplasmático se encuentran las partículas pequeñas derivadas de ribonucleoproteínas citoplasmáticas (scRNP), de las más importantes La/SSB y Rho/SSA, sin embargo estas pueden encontrarse hasta en un $30 \%$ de los casos a nivel nuclear. $5,6,7$

El papel propiamente de los ANA, como causa etiológica directa del Lupus, se ha establecido en base a teorías, que sugieren que los ANA se unen directamente a sus antígenos ya sean circulantes o in situ, resultando en el depósito de complejos inmunes, activación del complemento y mecanismos inflamatorios, que llevan a la subsecuente aparición de las manifestaciones características de la enfermedad. Esta teoría se ha desarrollado en base al depósito de complejos ADN/antiADN, principalmente encontrados a nivel de la membrana basal glomerular. Dentro de otras explicaciones que se han sugerido para esclarecer la causalidad de los ANA en LES, se resalta su presencia asociada a recaídas y actividad de la enfermedad. ${ }^{5}$

La participación de los ANAs en la patogénesis de la nefritis lúpica ha sido bien demostrada, por ende al encontrar casos reportados en la literatura que describen por ejemplo glomerulonefritis lúpica con ANAs negativos, obliga al clínico a cuestionarse la sensibilidad de la prueba de detección y descartar la presencia de un falso negativo. Sin embargo, se debe tener claro que pueden encontrarse ANAs negativos, mientras otros anticuerpos dirigidos contra otros antígenos nucleares se encuentran positivos, tal es el caso de los anticuerpos anti-dsADN y anti nucleosomas. Este fenómeno puede ser explicado debido a alteraciones en los mecanismos de apoptosis y alteraciones relacionadas con el pobre aclaramiento de autoantígenos derivados de los nucleosomas. ${ }^{6,7,8}$

En relación a la disfuncionalidad en los mecanismos apoptóticos, se ha descrito que dichas alteraciones, llevan a la exposición de antígenos derivados de nucleosomas hacia la circulación, así como de complejos ADN-histona que conllevan a la generación de anticuerpos contra estructuras de los nucleosomas. El hallazgo de pacientes con diagnóstico de LES o glomerulonefritis lupus like con ANAs negativos, llevó a determinar que la exposición de componentes del nucleosoma a la circulación tiene propiedades inmunogénicas más importantes que las de otros antígenos implicados en la aparición de anticuerpos como los anti-dsADN, de ahí que sea posible detectar anticuerpos contra nucleosomas o antihistonas, antes de que se logren determinar antidsADN. ${ }^{6,7,8,9}$

Actividad de la enfermedad en ausencia de ANA

Es difícil determinar el mecanismo etiológico que lleva al desarrollo de anomalías inmunológicas en ausencia de ANAs. Actualmente se ha reconocido el papel de los anticuerpos antinucleosomas como responsables del desarrollo de la patología aún en ausencia de ANAs. Por ejemplo, se sabe que los epítopos nucleosomales son capaces de activar células $\mathrm{T}$ específicas, en especial la respuesta Th1. Inclusive se han identificado modificaciones aniónicas y catiónicas específicas en las cadenas alfa de las células $\mathrm{T}$, que permiten su complementariedad con el complejo ADN-histona, de tal modo que dichos autoantígenos son capaces de activar una respuesta $\mathrm{T}$ altamente específica. Estas células T autoreactivas, así como las células B consecuentemente activadas por los epítopos nucleosomales, llevan al desarrollo de anticuerpos que a su vez son capaces de generar una respuesta inmune cruzada contra autoantígenos nucleares. Este mecanismo inclusive se ha logrado establecer a través de experimentación in vitro, en donde se ha implicado la presencia de epítopos nucleosomales con el desarrollo de glomerulonefritis en pacientes diagnosticados con de Lupus. ${ }^{6,7}$

Por otra parte, se menciona en la literatura que el desarrollo de inmunogenicidad a causa de los antígenos derivados de componentes del nucleosoma, se relaciona con alteraciones de los mecanismos de apoptosis y aclaramiento de cuerpos apoptóticos, que conducen a la exposición anormal de dichos péptidos. Específicamente se habla de una alteración en la fagocitosis de las células apoptóticas. Habitualmente el proceso de fagoci- 
tosis es neutral o no inmunogénico, sin embargo se han descrito señales inflamatorias mediadas a través de la modulación de citoquinas pro y antiinflamatorias, con especial importancia se describe la actividad de TNF- $\alpha$, IL10 e IL1B, inducida por la fagocitosis de células apoptóticas opsonizados con anticuerpos específicos, además se ha establecido un desbalance en las vías pro y antiinflamatorias, inducidas por antígenos virales y bacterianos, dirigido hacia la sobre expresión de señales proinflamatorias, siendo las responsables del desarrollo de los mecanismos patogénicos, incluso en pacientes con ANAs negativos. ${ }^{6,7,9}$

Teorías relacionadas con la negatividad del ANA en LES

Como principales implicados en la patogénesis del LES, el reconocimiento de los ANAs, constituye parte esencial del diagnóstico de esta entidad, sobre todo por su alta sensibilidad. Sin embargo desde su aparición se han empleado técnicas de inmunoflurescencia no estandarizadas para su determinación, de modo que resulta difícil para el clínico esclarecer cuando la ausencia de ANAs debe ser traducida como un falso negativo y cuando se trata de una entidad clínica desarrollada en ausencia de estos anticuerpos. ${ }^{5}$

Como ya fue mencionado, en la literatura se describe que cerca del $5 \%$ de la población diagnosticada con Lupus presenta ausencia de ANAs. Basado en las revisiones bibliográficas que datan desde 1976 hasta cerca 1998 está cifra está sujeta a una serie de factores distractores, dentro de los cuales destacan las técnicas de laboratorio empleadas, la administración de tratamiento inmunosupresor previa realización del análisis y la presencia de proteinuria como hallazgo asociado al momento del diagnóstico. Por lo tanto, los autores han sugerido el Lupus ANA negativo como una entidad sumamente rara cuando se han descartado estos elementos, incluso hay reportes en donde se emplean células HEp-2 como sustrato diagnóstico que llegan a reportar ANA positivos con diluciones mayores de 1:40 en cerca del $99 \%$ de la población analizada. $5,10,11$

\section{Métodos de Laboratorio}

Analizaremos inicialmente las diferencias en los métodos de laboratorio que se han empleado para el análisis de la presencia de ANAs. Inicialmente, se implementaron sustratos derivados de células de hígado de rata, bazo de humano, granulocitosis humanos, células de próstata humana y células de estirpe epitelial (HEp-2). La variabilidad de dicho sustrato se ha implicado como responsable de la heterogeneidad en la sensibilidad de las pruebas; se habla incluso de que algunos sustratos fueron antigénicamente ineficaces para permitir el desarrollo de anticuerpos, de tal modo que se documentaron variaciones en la negatividad del ANA al cambiar el sustrato de células de ratón a células de estirpe epitelial en humanos. . $^{5,12}$

En relación a la discordancia en estas pruebas de detección, las guías para el uso de tests inmunológicos para el diagnóstico y seguimiento de enfermedades reumatológicas, sugieren la opción de determinar isotipos de IgG de ANA, basados en que las determinaciones de subtipos $\operatorname{IgM}$ e IgA no mejoran la sensibilidad y por el contrario disminuyen la especificidad de la prueba. Además como primer paso en el diagnóstico de una enfermedad reumatológica cuando existe la sospecha clínica, se recomienda el uso de técnicas de inmunoflourescencia indirecta (IIF-ANA), debido a su alta sensibilidad, buena especificidad y costo accesible. Respecto al sustrato, se ha estandarizado el uso de células HEp-2, como material con mayor capacidad inmunogénica. Además permite el reconocimiento de diferentes patrones de IIF tanto nucleares como citoplasmáticos. En relación a las diluciones se considera que una dilución menor a 1:40 representa un ANA negativo, más de 1:40 y menos de 1:160, se considera positiva en títulos bajos, dependiendo de los síntomas se le dará seguimiento, mientras que si la dilución es mayor a 1:160 la prueba se considera positiva. ${ }^{13,14}$

Adicionalmente las guías mencionan el uso de otras metodologías tales como el ensayo inmunoenzimático (AIE-ANA), sin embargo este test puede tener fallas en la detección de patrones atípicos de inmunofluorescencia. Por otra parte, en el caso del ELISA para determinación de ANA, las guías recomiendan no utilizar este 
método a menos que tenga un $90 \%$ de concordancia con IIF y debe ser capaz de reconocer como positivos patrones en nucléolos y membrana nuclear. Por otra parte esta prueba debe ser confirmada con IIF de acuerdo a títulos y patrón, y en caso de documentarse una discordancia entre ambas pruebas se debe considerar la positividad del ELISA como un falso positivo. Finalmente, de los lineamientos que cabe recalcar en lo establecido por estas guías, destaca la recomendación de realizar mediciones de anticuerpos sólo en pacientes con signos claros de enfermedad reumatológica. Estas guías son solo parte de las acciones que se realizan con la finalidad de lograr resultados fidedignos respecto a incidencia de patología reumatológica, en especial LES. ${ }^{12,13}$

\section{Conversión del ANA}

La revisión de Arbuckle y colaboradores, logró describir que los procesos inmunológicos que se desarrollan en LES, son sumamente dinámicos, basados en la demostración de los cambios que se producen en los autoanticuerpos dependiendo de la etapa en cual se encuentre la enfermedad, dicha variabilidad está presente incluso antes de que se desarrollen las manifestaciones clínicas. Se describen en este artículo, tres etapas en el desarrollo de los anticuerpos, una primera fase caracterizada por una normalidad en el sistema inmune (ausencia de autoanticuerpos); la segunda llamada autoinmunidad benigna, donde dominan los anticuerpos antinucleares, anti-Rho, antiLa y anti fosfolípidos; y la tercera etapa donde se desarrolla patogenicidad derivada de autoinmunidad en la cual sobresalen los anticuerpos antidsADN, anti-RNP y anti-Sm. ${ }^{15}$

La aseveración anterior ha sido controversial, debido a que señala, una evolución dinámica en la generación de anticuerpos a medida que se desarrolla la enfermedad, sin embargo esta evolución como señala Ippolito y colaboradores es en lo referente a acumulación de nuevos anticuerpos y no en relación a la pérdida de ellos. Mientras tanto, otros autores como Song y colaboradores, por su parte señalan que la evolución si puede estar regida por la pérdida en expresió. Esto explicaría por qué ante niveles bajos de anticuerpos como ocurre cuando disminuye su producción, aumenta su consumo por la formación de complejos inmunes o cuando ocurre una pérdida significativa de las inmunoglobulinas, las pruebas diagnósticas son incapaces de detectar el ANA en el suero del paciente. De este modo es que analizaremos los cambios en el ANA de acuerdo a estas variables. ${ }^{15,16,17}$

\section{Presencia de Proteinuria}

En relación a la presencia de proteinuria al momento del diagnóstico, descrita en la literatura con cifras incluso de hasta $3 \mathrm{~g}$ en 24 horas, se menciona que estos niveles pueden llevar a la pérdida renal de inmunoglobulinas, principalmente de tipo $\mathrm{IgG}$, con lo cual podría no detectarse la presencia ANA a nivel sérico. Sin embargo dicha postulación ha perdido solidez, desde que las determinaciones séricas fueron comparadas con las detecciones a nivel del espacio pleural y a nivel urinario, donde el ANA resultó positivo, en presencia de enfermedad activa. ${ }^{5,17}$

\section{Uso de terapia inmunosupresora}

El uso de terapia inmunosupresora fue reconocida desde estudios iniciales como una variante que debe ser tomada en cuenta al momento de analizar el resultado de los ANAs. Song y colaboradores describen que la terapia a altas dosis glucocorticoides o inmunomodulares en pacientes con LES severo, puede generar inhibición del sistema inmune y disminuir la producción de anticuerpos, pudiéndose manifestar con la negatividad del ANA por la disminución en los títulos del anticuerpo. Mientras que en pacientes con enfermedad moderada, se ha determinado que el papel de dosis bajas de mantenimiento de glucocorticoides se relaciona con una estabilización de la enfermedad. Sin embargo, en el mismo estudio se teoriza que los anticuerpos necesariamente se producen y permanecen positivos a través del tiempo. 5,17

\section{Infección concomitante}

En pacientes con LES severo que a consecuencia de su condición desarrollan infecciones sistémicas, principalmente de etiología micótica, se ha descrito un descenso progresivo de los niveles de células B, células T CD4+ y de la expresión del HLA-DR en monocitos, mediado por la activación de la caspasa 9. Así mismo se describe un 
descenso en las inmunoglobulinas ( $\mathrm{IgG}, \operatorname{IgA}$, $\operatorname{IgM}$ ), en conjunto estos mecanismos llevan a la negativización de los ANAs, en pacientes con LES que al momento del diagnóstico se presentan con una infección severa, por lo tanto es otro de los factores ha tomar en cuenta al momento que se analiza una prueba de ANA. ${ }^{17}$

\section{Características clínicas de Lupus ANA negativo}

Inicialmente fue reconocida como una entidad caracterizada por la presencia de manifestaciones predominantemente cutáneas, las cuales también incluían manifestaciones de lupus eritematoso cutáneo subagudo, sin embargo estudios posteriores describen una gran variedad manifestaciones clínicas, como lo son la anemia hemolítica, glomerulonefritis, fenómeno de Raynaud, artritis, entre otras. Así mismo, dichas manifestaciones pueden variar desde un grado moderado hasta un grado severo, no obstante no se ha logrado demostrar un patrón de presentación típica que caracterice a esta entidad. Por otra parte, muchos de las variantes clínicas que fueron documentadas, derivan de estudios no estandarizados, en los cuales incluso pudieron haberse incluido variantes de Lupus ANA negativo no verdadero. 5,11,18

\section{CONCLUSIONES}

El Lupus ANA negativo, es una entidad conocida desde los años 70s, cuyo curso así como fisiopatología es poco comprendida, se han postulado hipótesis que pretenden explicar las alteraciones inmunológicas que llevan a su desarrollo, dentro de las más fuerte se señala la actividad de los anticuerpos contra nucleosomas, sin embargo su papel no está completamente dilucidado. Tampoco se ha podido precisar su incidencia, evolución y presentación clínica.

Como responsable de estas carencias, se considera que la falta de solidez en los estudios es la principal responsable, por lo cual se sugiere la elaboración de ensayos clínicos que utilicen métodos de laboratorio estandarizados para la determinación del ANA, así como el control de variables como la presencia de proteinuria y el tratamiento con terapia inmunosupresora con la finalidad de obtener datos fidedignos en relación a esta patología.

\section{BIBLIOGRAFÍA}

1. Tsokos G. Systemic Lupus Erythematosus. N Engl J Med. 2011;365:2110-21.

2. Maddison P, Provost T, Reichlin M. Serological findings in patients with "ANA negative" systemic lupus erythematosus. Medicine 1981;60:87-94.

3. Hepburn A, Charles P. Antinuclear factor. Rheumatology 2002;41:343-345.

4. Editors. Antinuclear antibodies: cause of disease or caused by disease? Rheumatology 2000;39:581-584.

5. Cross L, Aslam A, Misbah S. Antinuclear antibody-negative lupus as a distinct diagnostic entity-does it no longer exist? Q J Med 2004;97:303-308.

6. Burlingame R, Cervera R. Anti-chromatin (anti-nucleosome) autoantibodies. Autoimmunity Reviews 2002;1:321-328.

7. Koutouzov S, Jeronimo A, Campos H, et al. Nucleosomes in the pathogenesis of systemic lupus erythematosus. Rheum Dis Clin N Am 2004;30:529-558.

8. Pirkle J, Freedman B, Fogo A. Immune complex disease with a Lupus-like pattern of deposition in an antinuclear antibodynegative patient. Am J Kidney Dis 2013;62:159-164.

9. Mevorach D. The role of death-associated molecular patterns in the pathogenesis of systemic lupus erythematosus. Rheum Dis Clin N Am 2004;30:487-504.

10. Builes C, Durango I, Velásquez G. Lupus eritematoso sistémico con anticuerpos antinucleares negativos y anemia hemolítica. Acta Med Colomb 2010;35: 79-182.

11. Reichlin M. ANA negative systemic lupus erythematosus sera revisited serologically. Lupus 2000;9:116-119

12. Davis J, Moder K, Homburger H, et al. Clinical features of 39 patients with antibodies to extractable nuclear antigens despite negative antinuclear antibodies. Medicine 2005;84:208-217.

13. Tozzoli R, Bizzaro N, Tonutti E, et al. Guidelines for the laboratory use of auto- 
antibody tests in the diagnosis and monitoring of autoinmune Rheumatic Diseases. Am J Clin Pathol 2002;117:316-324.

14. Pham B, Albarede S, Guyard A, et al. Impact of external quality assessment on antinuclear antibody detection performance. Lupus 2005;14:113-119.

15. Arbuckle M, McClain M, Rubertone M, et al. Development of autoantibodies before the clinical onset of systemic lupus erythematosus. N Engl J Med 2003;349:152633.

16. Ippolito A, Wallace D, Gladman D, et al. Autoantibodies in systemic lupus erythematosus: comparison of historical and current assessment of seropositivity. Lupus 2011;20:250-255.

17. Song L, Ding F, Liu H, et al. Analysis of 15 patients with systemic lupus erythematosus manifesting with negative immunofluorescence anti-nuclear antibodies after treatment. Lupus 2012;21:919-924.

18. Locham K, Singh J, Garg R. ANA lupus negative erythematosus. Indian Pediatrics 2000;37:540-542.

\section{CONFLICTO DE INTERÉS Y/O AGRADE- CIMIENTOS}

Los autores declaran que no existió ningún conflicto de interés en el presente reporte. 